\title{
Productivity and Resource Use Efficiency in Wheat: A Stochastic Production Frontier Approach
}

\author{
Nasim Ahmad ${ }^{1 *}$, D.K. Sinha and K.M. Singh \\ Department of Agricultural Economics, Dr. Rajendra Prasad Central Agricultural University, Pusa (Samastipur)-848 125, Bihar, India \\ *Corresponding author: nasim.rau@gmail.com
}

\begin{abstract}
Farm level technical efficiency and its determinants in wheat production in the state of Bihar has been studied using stochastic frontier production function model. The average productivity of wheat was reported $28.43 \mathrm{q} /$ ha which was below the national average of $30.33 \mathrm{q} /$ ha during 2016-17. The resource inputs were found inelastic and not being properly utilized. All the resource inputs were found positive and significant at 1 per cent and 5 per cent level of probability except machine labour used which was negatively significant, indicating overuse of machine labour or costly machine labour. The mean input efficiency in production of wheat in the state was estimated to be 94 per cent, emphasizing that efficiency may be enhanced by 6 per cent. The factors influencing efficiency were identified as education, family size and landholding size. The mean technical efficiency was found to be 0.94 indicted that optimal and sustainable use of resource inputs may further raise the input use efficiency in wheat production by 6 per cent and consequently boost up the income of the wheat cultivators in the state.
\end{abstract}

Keywords: Wheat, Productivity, Stochastic Frontier analysis, Technical efficiency, Resource use

During last 60 years, India has turned from a food deficit to a food surplus nation, despite rapid increase in population from 361 million to 1.25 billion, due to remarkable development in food grain production in the nation (Anonymous 2016). It is not only the world's second largest producer of wheat, rice, fruits and vegetables and cotton but also the largest producer of milk and pulses. However, the performance of agricultural development has not been parallel across all the states. Some states like Punjab in the earlier days, Gujarat and more recently Madhya Pradesh have shown significant growth in agricultural sector and emerged ahead. Other states like Odisha and Uttar Pradesh have lagged behind in several development indicators. On the other hand, in Bihar between 2011-12 and 2015-16, the agricultural sector contracted at an annual rate of 0.1 per cent. The share of agriculture reduced from $25 \%$ to $18 \%$ during this period (Anonymous 2016).

Bihar ranks $6^{\text {th }}$ position in wheat production in India. Wheat occupies second rank among cereal crops after rice in the state. The area under wheat was recorded 2105.81 thousand ha, production 5984.84 thousand tonnes and productivity 28.43 q/ha during 2016-17. A remarkable increase in productivity has been noticed from $16.57 \mathrm{q} / \mathrm{ha}$ in 2014-15 to $28.43 \mathrm{q} / \mathrm{h}$ a in 2016-17 (Anonymous 2017). Moreover, productivity in agricultural crops remains low as compared to the national average, despite the rich natural resources for augmenting productivity in the state. The low productivity may be due to irrational exploitation of resources, improper adoption of technologies and lacking the proper policy formulation in the state. The situation is, further, getting worse due to rise in the cost of cultivation. The increase in agricultural production relies not only on land use but also on yield and efficiency. The yield may be increased either by improving technology or enhancing efficiency of the resources used in cultivation. Enhancing efficiency depending upon the cultivators is a matter of great concern. The study on technical efficiency is of vital importance for policy makers and planners to 
frame proper policies for augmenting efficiency or reducing inefficiency in agriculture.

Various studies have been carried out to estimate the technical efficiency of various crops in different states of the nation (Shanmugam, 2003; Reddy and Sen, 2004; Kalirajan and Bhende, 2007; Ahmad et al. 2017). But, no study on resource use efficiency in wheat seems to have been carried out in Bihar. The state has diverse climatic condition, fertile land and abundant of groundwater and huge capacity of workforce, due to these reasons the state is targeted as the origin of Second Green Revolution in the country. In this investigation, an attempt has been made to find out the level of technical inefficiency and impact of various farm related socio-economic factors on technical inefficiency in wheat production in the state.

\section{Technical efficiency measurement using Stochastic Production Frontier model}

Since the pioneering work by Farrell (1957), a number of approaches to efficiency measurement have emerged. The two main approaches that have been widely used in the efficiency measurement are parametric Stochastic Frontier Analysis (SFA) initially proposed by Aigner et al. (1977) and Meeusen and Van den Broeck (1977); and nonparametric Data Envelopment Analysis (DEA) initially developed by Charnes et al. (1978).

Choosing between the Stochastic Frontier Analysis (SFA) and Data Envelopment Analysis (DEA) approaches for measurement of efficiency has been controversial and depends upon the objective of the research, the type of industry and the availability of data (Wadud and White, 2000). The DEA is a nonparametric approach. It does not rely on the definition of a functional form characterizing the underlying technology and therefore, avoids misspecification problems.

However, a drawback of this technique is that it is deterministic and ignores the stochastic error term which implies that deviations from the frontier are fully attributed to inefficiency effects. As a result, technical efficiency ratings obtained from the nonparametric approach are generally lower than those obtained under the parametric SFA alternative (Coelli and Battese, 2005; Kumbhakar and Lovell, 2000). The main advantage of the parametric SFA approach is that it incorporates a composed error term with a two-sided symmetric term and a onesided component which permits to differentiate between inefficiency and exogenous shocks. The one-sided component exhibits inefficiency, while the two-sided error captures the random effects and exogenous shocks outside the control of the production unit, including measurement errors and other statistical noise typical of empirical relationships.

This study adopts the stochastic frontier function approach since agricultural crop production exhibits random shocks and there is a need to separate the influence of stochastic factors (random shocks and measurement errors) from the effects of other inefficiency factors by assuming that deviation from the production frontier may not be entirely under the control of farmers. Production efficiency is widely used in agricultural economics to assess the performance of farmers. Efficiency can be divided into two concepts; the technical efficiency also known as output oriented efficiency, and allocative efficiency also referred to as the input-oriented efficiency.

Allocative efficiency can be considered as the ability of a farm to use the inputs in optimal proportions given their respective prices and technology i.e. getting optimal output or profits with the least cost of production. Technical efficiency, on the other hand, is the ability of a farming unit to produce a maximum level of output given the level of inputs (Farrell, 1957). In measuring output-oriented technical efficiency, the inputs are exogenously given and the objective is to maximize output as the only choice variable.

According to Sunday et al. (2013), Stochastic Production Frontier analysis indicates the maximum expected output for a given set of inputs. It is derived from the production theory and based on the assumption that output is a function of inputs and efficiency of the cultivator in using these inputs. This model assumes that the boundary of production function is defined by "best practice" firms. It, therefore, indicates the maximum potential output for a given set of inputs. The difference between observed output and potential output is generally attributed to combination of inefficiency and random error. 
Battese et al. (1995) and Fari et al. (2001) defined the Stochastic Production Frontier (SPF) as given below:

$$
\begin{aligned}
& Y_{j}=f\left(X_{i j} ; \beta\right) \exp \epsilon \\
& \epsilon=V_{j}-U_{j}
\end{aligned}
$$

where, $j=1,2, \ldots \ldots n$ and $i=1,2, \ldots 5$

Where $Y_{j}$ is the output of $j^{\text {th }}$ firm, $X_{i}$ is a vector of factor inputs to be used by $j^{\text {th }}$ firm, $\beta$ is the vector of unknown parameters to be estimated, $\theta$ is a composite error term, $V_{j}$ is the stochastic error term which is associated with random factors outside the farmers control such as topography, weather and it is independent of $U_{i}$. The $U_{j}$ is a one sided error representing the technical inefficiency of firm $j$. Both $V_{j}$ and $U_{j}$ are assumed to be independently and identically distributed with constant variance and zero mean.

The technical efficiency (TE) of a firm using Stochastic Production Frontier is given as:

$$
\mathrm{TE}=\frac{Y_{j}}{Y_{j}^{*}}=\frac{\text { Observed output }}{\text { Frontier output }}=\frac{f\left(X_{i j} ; \beta\right) \exp \left(V_{j}-U_{j}\right)}{f\left(X_{i j} ; \beta\right) \exp \left(V_{j}\right)}
$$

\section{MATERIALS AND METHODS}

The study is based on plot level data collected under Comprehensive Cost of Cultivation Scheme, Ministry of Agriculture and Farmers Welfare, Government of India running in the state of Bihar for the year, 2014-15. The total number of wheat growing farmers was 425 out of 450 respondents. The technical inefficiency of individual farm was carried out using stochastic frontier production function.

\section{Model specification for wheat cultivators}

The empirical stochastic frontier production model is specified as given below:

$$
\ln Y_{j}=\underset{\ln X_{5}+\left(V_{j}-U_{j}\right)}{\beta_{j}+\beta_{1} \ln X_{1}+\beta_{2} \ln X_{2}+\beta_{3} \ln X_{3}+\beta_{4} \ln X_{4}+\beta_{5}}
$$

Where,

$$
\begin{aligned}
& \mathrm{Y}=\text { Production of wheat }(\mathrm{q} / \mathrm{ha}) \\
& \mathrm{X}_{1}=\text { Human labour }(\mathrm{hrs} / \mathrm{ha}) \\
& X_{2}=\text { Machine labour }(\mathrm{hrs} / \mathrm{ha}) \\
& X_{3}=\text { Fertilizer }(\mathrm{kg} / \mathrm{ha})
\end{aligned}
$$

$X_{4}=$ Seed $(\mathrm{kg} / \mathrm{ha})$

$\mathrm{X}_{5}=$ Groundwater (cum/ha)

$\mathrm{V}_{j}=$ Stochastic error term

$\mathrm{U}_{\mathrm{j}}=$ Technical inefficiency effect predicted by the model

The a priori expectation is that the coefficients of all the inputs $X_{1}$ to $X_{5}$ which are $\beta_{1}$ to $\beta_{5}$ should be positive, respectively.

The model was estimated using the computer programme FRONTIER 4.1 (Coelli, 1996) to assess simultaneously the parameters of stochastic production frontier and the technical inefficiency impact.

The inefficiency model is as follows:

$$
U_{j}=\delta_{0}+\delta Z_{i j}
$$

Where:

$\mathrm{U}_{\mathrm{j}}=$ Technical inefficiency effect

$\mathrm{Z}_{\mathrm{ij}}=$ Values of explanatory variables ( $\mathrm{i}^{\text {th }}$ variable) for technical inefficiency effects for the $j^{\text {th }}$ farmer (where $j=1,2, \ldots \ldots . . n$ and $i=1,2, \ldots \ldots, 5$ )

$Z_{1}=$ Age of the $j^{\text {th }}$ farmer

$Z_{2}=$ Educational level of $j^{\text {th }}$ farmer

$\mathrm{Z}_{3}=$ Family size of $\mathrm{j}^{\text {th }}$ farmer

$Z_{4}=$ Area under crop of $j^{\text {th }}$ farmer (ha)

$Z_{5}=$ Total land holding size of $j^{\text {th }}$ cultivator.

The specification of the model for inefficiency effects in equation (2) implies that if the independent variables of the inefficiency model have a negative $(-\mathrm{v})$ sign on the estimated parameter, then the associated variable has positive impact on efficiency, while positive sign indicates that the reverse is true.

\section{RESULTS AND DISCUSSION}

The summary statistics of different variables used in the model to estimate the inefficiency has been presented in Table 1 . The average production of wheat was found $27.22 \mathrm{q} / \mathrm{ha}$ in Bihar (based on plot level data of cost of cultivation scheme) with an average use of human labour $184.41 \mathrm{hrs} / \mathrm{ha}$, machine labour $31.92 \mathrm{hrs} / \mathrm{ha}$, seed $115.24 \mathrm{~kg} / \mathrm{ha}$, fertilizer $143.80 \mathrm{~kg} / \mathrm{ha}$ and groundwater 5694.3 cum/ha. Still the productivity of wheat is not at par with the national average indicating thereby 
some inefficiency existing in production of wheat in the state. According to Directorate of Economics and Evaluation, Government of Bihar, the average productivity of wheat was also reported $28.43 \mathrm{q} / \mathrm{ha}$ which was also below the national average of 30.33 q/ha during 2016-17.

Table 1: Input and output levels for wheat production in Bihar

\begin{tabular}{ccccc}
\hline Variables & Maximum & Minimum & Mean & $\begin{array}{c}\text { Standard } \\
\text { Deviation }\end{array}$ \\
\hline $\begin{array}{c}\text { Output (q/ha) } \\
\text { Human labour } \\
\quad \text { (hrs/ha) }\end{array}$ & 520.50 & 13.49 & 27.22 & 2.99 \\
$\quad \begin{array}{c}\text { Machine } \\
\text { Labour (hrs/ha) }\end{array}$ & 76.08 & 0.00 & 184.41 & 92.07 \\
$\begin{array}{c}\text { Fertilizer } \\
\text { (kg/ha) }\end{array}$ & 471.00 & 0.00 & 143.80 & 42.10 \\
$\begin{array}{c}\text { Seed (kg/ha) } \\
\text { Groundwater }\end{array}$ & 154.17 & 67.80 & 115.24 & 12.90 \\
draft (cum/ha) & 18701.50 & 0.00 & 5694.30 & 3712.60 \\
\hline
\end{tabular}

\section{Resource use efficiency in wheat cultivation}

The resource use efficiency aimed at investigating the technical relationship between resource inputs used and output which were not efficiently managed by the cultivators, resulting in low productivity in wheat in Bihar. The Maximum Likelihood Estimates (MLE) of the stochastic frontier production model and the inefficiency model were estimated and the results were shown in Table 2. The estimates depicted that the coefficients of the resource inputs revealed positive sign except for machine labour (hrs/ha), thus, conformed to the a priori expectation. Human labour, fertilizer and groundwater used were found statistically significant at 5 per cent level of probability. These inputs were found to be relatively inelastic and not being used properly. Thus, optimal use of these resources may increase the productivity level of wheat.

The estimated coefficient of seed was observed to be 0.037 . This indicates that $10 \%$ increase in seed, other inputs being constant, increases wheat productivity by $3.7 \%$. This revealed that seed in the state was inelastic too or in other words, there is lack of quality seed in the state. The estimated coefficient of machine labour was observed negative and significant at $1 \%$ level of probability indicating thereby excess use of machine labour in wheat cultivation. The number of farm holdings was about 1.61 crores of which $91 \%$ found marginal and thus, use of machines on fragmented land may be a costly affair. The results indicated the importance of quality seed in wheat cultivation in the state and mechanized way of farming being unaffordable and costly as majority of cultivators were marginal and small.

Table 2: Parameter estimates of stochastic frontier production function for wheat production in Bihar

\begin{tabular}{cccc}
\hline Variables & Coefficient & $\begin{array}{c}\text { Standard- } \\
\text { error }\end{array}$ & t-ratio \\
\hline Constant & $3.034^{*}$ & 0.217 & 13.983 \\
Human labour (hrs/ha) & $0.008^{* *}$ & 0.004 & 1.940 \\
Machine labour & $-0.007^{*}$ & 0.005 & -1.332 \\
(hrs/ha) & $0.021^{* *}$ & 0.011 & 1.862 \\
Fertilizer (kg/ha) & 0.033 & 0.049 & 0.687 \\
Seed (Kg/ha) & $0.003^{* *}$ & 0.002 & 1.674 \\
Groundwater used & -0.448 & 1.719 & -0.261 \\
(cum/ha) & $0.012^{* *}$ & 0.008 & 1.552 \\
Constant & $-0.029^{* *}$ & 0.016 & -1.771 \\
Age (years) & $-0.014^{* *}$ & 0.006 & -2.303 \\
Education & $0.152^{* *}$ & 0.032 & 4.741 \\
Family size & $-0.080^{* *}$ & 0.021 & -3.753 \\
Area under crop (ha) & $0.065^{* *}$ & 0.025 & 2.643 \\
Landholding Size $($ ha) & & 0.061 & 13.876 \\
Sigma-squared $\left(\sigma^{2}\right)$ & $0.849^{* *}$ & - & - \\
Gamma $(\gamma)$ & 346.16 & - & - \\
Log likelihood & & & \\
function & 0.942 & - & \\
Mean Technical & & & \\
Efficiency & & & \\
\hline
\end{tabular}

* ** indicates significant at $1 \%$ and $5 \%$ probability level, respectively.

\section{Socio-economic factors influencing efficiency of wheat production}

The inefficiency model as presented in Table 2 revealed that only the estimated coefficients of education, family size and landholding size confirmed to the a priori expectation. A negative coefficient in efficiency model shows the positive effect on efficiency i.e. it increases the technical efficiency and production, while a positive sign indicates negative impact on efficiency i.e. decreases technical efficiency, resulting in decrease in production of wheat. The coefficient of age was found to be 0.012 and significant at $5 \%$ of probability level. This implies that there is positive relationship 
between age and technical inefficiency in wheat production i.e. as the age increases, the efficiency declines. Age of the cultivators play an important role in decision making and has contribution towards cultivators general learning and right judgments in time. This reason for this relationship may be due to the fact that old age farmers may be unwilling to take risk and their thought may be traditional. The other cause may be to evade frequent experimentation with the new advent of technologies. The finding is consonant with the finding of Munir et al. (2002) conducted in Pakistan.

The coefficient of education was found negative thus; conform to the a priori expectation. The coefficient of education (-0.029) was found to be negative reflecting positive relationship between technical efficiency and education. This shows that increase in formal education would decrease inefficiency or in other way, increase the production efficiency. This result very clearly showed that education is an important factor for enhancing or boosting agricultural productivity. Educated farmers have better access to new technologies of farming and prices of inputs. Better educated cultivators also have eagerness to adopt modern inputs more optimally and efficiently. Hence, this finding suggested that educated and young people may be encouraged to indulge themselves in faming profession.

The coefficients of landholding size and family size were estimated to be -0.080 and -0.014 , which indicated that these factors had positive impact on technical efficiency of the wheat growers of the state. Mechanization of large holding is easy and cost effective as compared to small and marginal land holdings. Number of family members will provide more hands for farming and will reduce dependency on hired labour. Hence, wheat growers may be able to manage their farms efficiently as the labour scarcity in the state for cultivation purpose is also a big problem.

The variance parameters of the frontier production model were Sigma square $\left(\sigma^{2}\right)$ and Gamma $(\gamma)$. The Sigma squared indicates the total amount of variance found in the model. It was found 0.065 which was statistically significant at 5\% level of probability. Gamma explains the systematic effects that are unexplained by the production function and the dominant sources of random errors. It was estimated 0.849 . This shows that $85 \%$ variation in wheat production was as a result of technical inefficiencies of the cultivators. Thus, the results indicate that inefficiencies were present in production of wheat in the state. The mean Technical efficiency of wheat cultivators of the state was estimated $94 \%$ reflecting that efficiency can be enhanced by $6 \%$ to boost the productivity of the wheat in Bihar.

\section{CONCLUSION}

From the above discussion it may be concluded that the resource use efficiency in production of wheat was observed to be rather low. It was measured in terms of technical efficiency and the mean technical efficiency in the production of wheat could be estimated as much as $94 \%$, which indicated that the efficiency of resource use in the production of wheat may be enhanced by $6 \%$ with judicious utilization of the resource inputs like quality seeds, fertilizers, irrigation and proper combination of inputs in the harmony or conformity with their input prices. Out of total random variation found in the model, nearly $85 \%$ variation was on account of technical inefficiency, which may be improved by the farmers through proper utilization of the scarce resources. The factors causing inefficiency were identified as education, family size and landholding size of the farmers, reflecting that educated people have more access to the knowledge regarding modern technologies and have capacity to bear risk. Family size may help in reducing dependency on hired labour as labours for agricultural purposes are of great concern for the cultivators. Small and fragmented lands are causing inconveniences in using machineries. Fabrication of mechanical devices suitable for marginal and small farmers may help in enhancing productivity and reducing production cost.

\section{REFERENCES}

Aigner, D.J., Lovell, C.A.K. and Schmidt, P. 1977. Formulation and estimation of stochastic frontier production functions. Journal of Econometrics, 6: 21-37.

Anonymous 2016. Annual Report 2015-16. Department of Agriculture, Cooperation $\mathcal{E}$ Farmers Welfare Ministry of Agriculture $\mathcal{E}$ Farmers Welfare Government of India.

Anonymous 2016. Status Report of Bihar 2015-16. Directorate of Economics and Statistics, Government of Bihar. 
Anonymous 2017. Annual Report 2016-17. Department of Agriculture, Cooperation \& Farmers Welfare Ministry of Agriculture \& Farmers Welfare Government of India.

Battese, G.E. and Coelli, T. 1995. A Model for technical inefficiency effects in a stochastic frontier production function for panel data. Empirical Economics, 20: 325-332.

Charnes, A., Cooper, W.W. and Rhodes, E. 1978. Measuring the efficiency of decision makingunits. European J. of Operational Research, 2: 429-444.

Coelli T.J. 1996. A Guide to FRONTIER version 4.1c: A computer program for stochastic frontier production and cost function estimation; mimeo. Department of Econometrics University of New England, Armidale, NSW Australia.

Coelli, T.J. and Battese, G.E. 2005. An Introduction to Efficiency and Productivity Analysis.

Fari, A., Paul, F. and Alistair, B. 2001. Production technologies and technical efficiency: evidence from Portuguese manufacturing industry. A publication of the University of Minho, Portugal.

Farrell, M.J. 1957. The Measurement of Productive Efficiency. J. Royal Statistical Society. Series A (General).
Kalirajan, K.P. and Bhende, M.J. 2007. Technical efficiency of major food and cash crops in Karnataka (India). Indian Journal of Agricultural Economics, 62(2): 176-192.

Kumbhakar, S.C. and Lovell, C.K. 2000. Stochastic Frontier Analysis. Cambridge University Press, Cambridge.

Meeusen, W. and Van den Broeck, J. 1977. Efficiency estimation from Cobb-Douglas production functions with composed error. International Economic Review, 18: 435-44.

Reddy, A.R. and Sen, C. 2004. Technical inefficiency in rice production and its relationship with farm-specific socioeconomic characteristics Indian Journal of Agricultural Economics, 59(2): 259-267.

Shanmugam, R.K. 2003. Technical efficiency of rice, groundnut and cotton farms in Tamil Nadu. Indian Journal of Agricultural Economics, 58(1): 101-114.

Sunday, B.A., Obot, D.A., Samuel, J.U. and Daniel, E.J. 2013. Analysis of the Physical Capacity Utilization in the Sugar Industry in Nigeria. British Journal of Economics, Management \& Trade, 3(2): 9-13.

Wadud, A. and White, B. 2000. Farm household efficiency in Bangladesh: a comparison of stochastic frontier and DEA methods. Applied Economics, 32: 1665-1673. 